\title{
Transition pathways to fully automated driving and its implications for the sociotechnical system of automobility
}

\author{
Eva Fraedrich $^{1} \cdot$ Sven Beiker ${ }^{2} \cdot$ Barbara Lenz $^{3}$
}

Received: 18 March 2015 / Accepted: 23 July 2015 / Published online: 26 August 2015

(C) The Author(s) 2015. This article is published with open access at Springerlink.com

\begin{abstract}
The advent of fully automated road vehicles is a topic currently getting attention in the field of transport as well as futures research: the technology is assumed to radically change the way we move in the future as well as to expand and differentiate existing mobility concepts. Still, the implications of automated driving are first and foremost discussed from a technological point of view and uncertainty about how this transition might take place remains. The embedding in the system of automobility respectively the transport system as a whole, currently lacks analytical as well as empirical examination. In our paper, we will discuss the topic in relation to three possible sociotechnical transition scenarios: (1) evolution, (2) revolution and (3) transformation. We will extrapolate different scenarios of automated driving based on current technical, economic, infrastructural, spatial, and transport developments and discuss its consequences for the transport system and mobility concepts.
\end{abstract}

Keywords Autonomous driving · Fully automated driving · Sociotechnical transformation - System of automobility

Eva Fraedrich

eva.fraedrich@geo.hu-berlin.de

1 Geography Department - Transport Geography, Humboldt-Universität zu Berlin, Unter den Linden 6, 10099 Berlin, Germany

21102 Clark Way, Palo Alto, CA 94304, USA

3 German Aerospace Center, Institute of Transport Research, Rutherfordstraße 2, 12489 Berlin, Germany

\section{Introduction}

The advent of fully automated road vehicles - meaning cars that drive without the need of a human driver - is currently a much discussed topic. It is also getting attention in the field of transport as well as futures research: The technology is assumed to radically change the way we move in the future, to have daunting influence on our societies and economies as well as to expand and differentiate existing mobility concepts [cf. 1, 2]. At present, the excitement about the technology in the making seems tremendous - we are confronted with media reports on 'machine-cars that consume drastically less fuel' [3] or 'cities with less congestion and noise' [4], 'people that will stay individually mobile into old age' [5] and 'eras ending where only owning an automobile represented freedom and mobility' [6]. Statements like these pick up on different levels and elements (e.g. the technological development of the vehicle itself, the traffic and infrastructure system, potential users of the future technology or cultural aspects) that are all involved in the genesis of fully automated driving. Whether or not these expectations quoted will proof realistic (or even the opposite will hold true!) when fully automated vehicles become part of the transport system, they also point towards the necessity to examine the technology beyond pure technical aspects. New technologies do not appear 'out of nowhere'-their emergence itself is embedded in an existing sociotechnical system — or moreover, technology deployment is strongly linked to paying "adequate attention to [its] appropriateness for a particular physical environment or their impact on social structure and needs" [7, p. 92]. Prominent examples for failing this requirement exist throughout technology history, e.g. the case of 'Aramis' [8] or the defeat of the steam automobile [9]. The 'meaning' of technologies is only comprehensible in relation to the societal urgency that they address (e.g. in relation to mobility, time use, habitation). 
While at present uncertainty remains about when, how, or if fully automated vehicles will be implemented into our transport system and complement or replace conventional road vehicles, we are nevertheless able to identify scenarios, based on current (known) developments and deviate possible and maybe even radical implications that display significance on different levels or for different elements. An examination of these relevant elements and processes in relation to technology is therefore crucial at this early point of technological development. It also relates to a more contemporary understanding of transport (studies) where a shift "from a primary focus on technology fix to a [...] 'transport in society' perspective" has taken place for quite some time [10, p. 29].

The aim of this paper is to discuss different scenarios of fully automated driving with respect to their embedding in a sociotechnical context to gain comprehension of consequences for the future transport system and mobility. We want to provide a better understanding of a possible transition and identify aspects that enable or constrain the implementation as well as the adoption of fully automated vehicles in the future. We use a holistic approach to obtain a comprehensive view on the topic: the paper first introduces a multi-level perspective on automobility as an entangled sociotechnical system. In the context of this "system of automobility" [11], we will, second, discuss whether a possible transformation can be stated in the system that would support the emergence of fully automated vehicles in a nottoo-distant future. Third, we will elaborate on what is meant by 'fully automated driving', what are common motivations behind the technology and also, what is the current development status on different levels. Based on these considerations we will fourthly extrapolate three scenarios as potential projections of how the introduction of fully automated vehicles might play out and discuss their implications in relation to the future transport system and (auto)mobility before we conclude with an outlook regarding the needs for future(s) research in the field.

\section{New technologies in relation to sociotechnical transformation processes}

Over the past 20 years plenty of empirical and theoretical work has been devoted to the topic of 'sociotechnical transition', mostly from an economic sciences point-of-view, namely evolutionary theories [cf. 9, 12-16]. These perspectives deal with interactions and entanglement of technical artefacts with organizations/institutions, actors, structures, and social practices within societies that mutually fulfill social functions [cf. 9]. The analytical category 'sociotechnical system' is thereby thought appropriate to display how social functions ${ }^{1}$ are actively produced in processes where societal groups act in systemic interactions - these groups are not only part of the production, development and refinement of a sociotechnical system, they also bring in various interests, perceptions, values and norms, preferences, strategies and resources. Along with this assumption comes the notion that it is never technology alone (e.g. automated driving technology) that is able to induce a change in a sociotechnical system but rather the many complex interactions between societal groups, different actors as well as the alignment of specific factors. Such a change will then 'transform' a society fundamentally in its existing practices, attitudes, norms and values - or put in other words: sociotechnical transformation fundamentally changes the way how a system fulfills specific societal needs [12, p. 91].

To display change processes, Geels and others apply the multi-level perspective (MLP), a middle-range theory that consists of three analytical levels: landscape, regime and niche [cf. 19]. 'Regime' describes the level where practices, societal functions and beliefs are constantly enacted, shaping routines, regulations, material and institutional resources and settings, social groups, behavioral norms, cultural meaning, etc., therefore stabilizing the functioning of the system and forming its "deep structure" [21, p. 27]. 'Stabilizing' simultaneously means that new technologies will have a 'hard time' of breaking through if they comprise altered interests, require new rules and/or result in alternative routines. 'Landscape' and 'niche' are concepts derived from the regime level and are at the same time highly correlated with it [21, p. 26]. 'Niches' are described as protected spaces $^{3}$ within the sociotechnical system. Technical innovations can be developed without too much pressure from the market, society, politics, etc., while also facing great uncertainty $[9$, p. 450$]$. Niches normally provide specific sets of resources, cultures and shape social networks-which essentially make them small sociotechnical systems themselves. Individual actors, specific technologies and local practices are of particular importance when

\footnotetext{
$\overline{1}$ The reference to the 'functionality' of a system is a specific way of thinking, though, that received a lot of critique since its genesis in the late 19th century - on the one hand because the distinction between causes and consequences of phenomena becomes blurry, and on the other hand because identifying the functions of these phenomena does not necessarily explain them [cf. 17], pp. 90]. This also proves significant in relation to (auto)mobility, as automobile practices cannot only be derived from societal needs - but rather arise because they become feasible by the car [cf. $18]$.

${ }^{2}$ Whereas in earlier works of this approach the three levels were also characterized as 'macro', 'meso' and 'micro' to indicate a "nested hierarchy" [cf. 20]: 1215], this was given up later as a response to the accusation of inadequately overemphasizing vertical circulations within transition processes, thus obstructing the view on social practices as constitutional elements of a sociotechnical system [21, 22].

${ }^{3}$ Space in this context refers to either, real' places and territories but can also refer to virtual or imaginary places.
} 
developing alternatives to the status quo [16]. But to gain momentum outside the niche and eventually break through to the regime level to initiate change, niche innovations also highly depend on developments on the regime as well as on the landscape level $[14,23]$. The term 'landscape' refers to particular characteristics and aspects of a system that cannot be changed easily or deliberately, e.g. spatial/environmental structures like the dependence on finite resources ('peak oil'), demographic change, or globalization and individualization constructions. Often, the landscape level is described as forming an "exogenous environment" to the other levels [20, p. 1215] — we would, however, rather suggest considering 'landscape' as a contextual category that constitutes processes on the regime and niche level but is in reverse also constituted by them. Figure 1 shows an exemplary (and only fragmentary) structure of the levels with regard to the sociotechnical system of automobility, based on the MLP - although only referring to the different levels and exemplary, analytical elements, without visually representing the dynamic processes that occur within the categories as well as between them (see [e.g. 21, 23] for more accurate illustrations).

The analytical tripartition of the MLP is a helpful approach when focusing on possible changes in sociotechnical systems in different ways: it provides a long-term perspective that seems appropriate to sociotechnical changes-which are less likely to happen as a sudden, 'over-night' change than as a process that leads to gradual and evolving alteration. It also identifies multiple levels, actors, groups and domains that are involved in this change. And by introducing the "niche" concept, it provides a systemic level that is of particular importance when it comes to the emergence of new technologies or radical innovations.
However, the approach was criticized for "unduly [emphasizing] processes of regime change which begin within niches and work up, at the expense of those which directly address the various dimensions of the sociotechnical regime or those which operate 'downwards' from general features of the sociotechnical landscape" [24 p. 19]. The MLP was also accused of not providing great clarity about the scope of empirical topics, especially when it comes to the regime level, and of not explicitly highlighting the role of power practices and politics, respectively, how knowledge and practices are continuously (re)produced [15, 24]. Moreover, the approach tends to focus on technical artefacts or social entities that influence each other in complex ongoing processes rather than regarding hybrid forms of sociotechnical entities $[25,26]$ - it also does so within apparent boundaries of a specific system. As we will see in the discussion on possible scenarios of fully automated driving, a strict focus on one system alone could be insufficient sometimes. Before we shed light on possible prevailing shifts in the sociotechnical system of automobility we will attempt to briefly describe how this system can be characterized.

\section{The 'system of automobility'}

The car is not just a means of transportation, but as a technological artefact it is deeply embedded in our (western) societies. This embedment refers to the compounded object itself but also to the industry where it originates from, to consumption practices by its users and owners, to the net of interconnected industries, distribution, maintenance and building facilities, as well as to surrounding land use planning, road advertising, housing and accommodation, etc., to the 'car
Fig. 1 Multi-level perspective on automobility

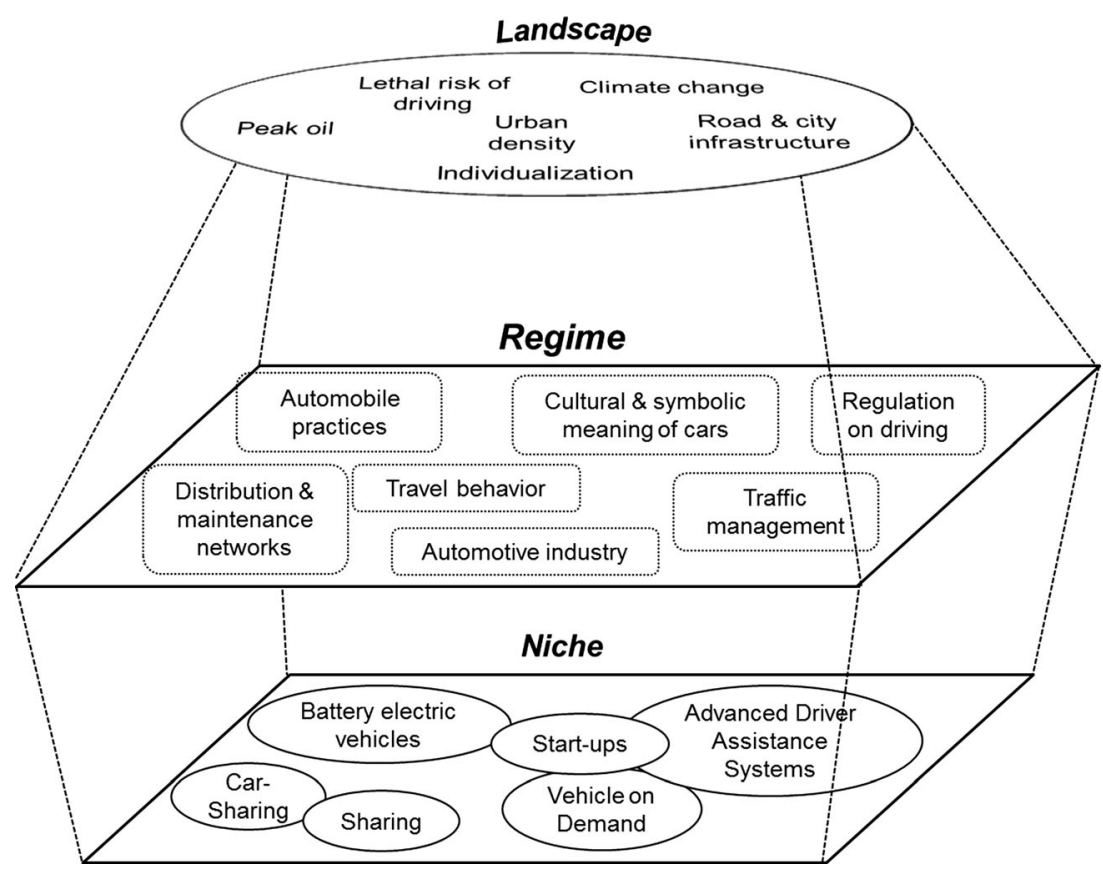


culture' with its corresponding symbols, images and metaphors, and to the consumption of environmental resources [11, pp. 25]. To determine this denotation of the car, it is therefore necessary to gaze beyond the material artefact and its characteristics and to consider the system that organizes and (re)produces its existence. This 'system of automobility' can be described as a net of material and social elements, a global system, comprising the industrially manufactured object of the car, its social meaning as one major item of consumption, its economic meaning within the involved industries, services and patterns of dwelling, its dominating position with regard to other modes of movement and transportation, its cultural associations as well as its ecological impacts. [21, p. 608].

The system of automobility could be described in a variety of ways [cf. 11], but an understanding of it being systemic and structured first and foremost leads to the appraisal that it does not suffice to focus on car use as a way to express something respectively add specific meaning to our lives or to decode specific cultural meanings of car use [cf. 27-29] —although this gives valuable hints on the significance of the automobile within our societies. However, it is rather an autopoietic multitude of regulations, institutions, politics and practices that continually ensure, reproduce and market the use of cars that has to be regarded [11, p. 27, 29, p. 5,]. As such, automobility is (1) one of the sociotechnical institutions our modernity is significantly constituted of; (2) a set of political institutions and practices that regulates and forms automobility and simultaneously mediates its consequences; (3) an ideological and discursive formation that incarnates ideals of freedom, privacy, movement, progress and autonomy that in turn legitimates its technical artefacts (road vehicles, streets, maintenance buildings, etc.); and (4) a set of possibilities to experience the world while blurring the boundaries between human and machine, nature and culture [30, pp. 2].

\section{Sociotechnical change ahead?}

After more than a century where the automobile ruled our (western) mobile world, the predominance of this powerful artefact finally is about to reach its limits-at least, this is a rumor, currently spread widely within the social sciences, transport studies and sociology, although the direction of change is not yet clear [cf. 11, 18, 31, 32]. In fact, there is some data particularly on changes in everyday travel behavior that seems to support this assumption [cf. e.g. 33] — but all in all, studies on actual trends on car use and ownership do not suggest the automobile losing its predominance at present [34, 35]. Although, there might be some ruptures that could have substantial influence on the hegemony of the system of automobility in the medium or the long term, these ruptures are currently restricted to specific socio-economic groups as well as specific geographic sites (e.g. urban areas), i.e. "these post- automobile mobility subjects and practices depend on specific infrastructures and are therefore tied to cities and inter-city connections and on a specific form of network capital [...], making them at present options for the urban elites and the socalled creative class only" [18, p. 619]. For the vast majority of people who use and/or own cars, the automobile still seems to have an immense significance when fulfilling their daily needs [36, p. 114]. In fact, it appears to be a difficult thing to change our relationship to the automobile, as we are so deeply linked to this system in many ways (e.g. feeling the car, the need for speed, etc.) [cf. 37]. In a recent, representative poll among young adults from Germany, Austria and Switzerland, only six percent of the respondents between 18 and 24 years stated that owning a car is not up to date any more [38, p. 68]. And a nationwide German newspaper wrote only in January 2015 that the 'love' for the car is possibly not over yet, stating that the car will not become less important but rather will have to shift from a simple flivver ${ }^{4}$ to a smart companion [39]. However, as, with advanced automated driving functions, more software and computer systems enter the car, it also more "becomes a world in itself" [26, p. 51] changing at least the way we move in these vehicles - which might eventually also show effects within the system of automobility itself. The next section will focus on a few of these effects after making some general remarks on the technology and its development.

\section{Fully automated driving - a vision in motion}

The vision of fully automated cars that operate without human intervention needed is not novel - in fact, it is part of a history almost 100 years old and ever since haunted the imaginations of the technological feasible, above all in cultural objectivations like images and films [cf. 40]. It is only recently, that the dream of the 'auto-automobile' finally seems to come true, potentially heralding another mobile revolution [41, p. VII]. What is currently labeled as 'fully automated', 'autonomous', 'self-driving', or 'driverless' refers to the automation of road vehicles: computer systems execute navigation, longitudinal and lateral control of a vehicle - a human driver is not necessary any more [42]. Possibly, there is not any human present in the vehicle, for instance when the vehicle is underway to a certain pick-up point.

Fully automated driving is currently one of the predominant visions (in the form of a technological fix) that industry, academic, and public sector groups pursue to address challenges that personally used automobiles present; or, in other words, dissolving antagonisms that are - on the landscape

\footnotetext{
"The old-fashioned term 'flivver', sometimes also known as 'jalopy', 'clunker' or 'rust bucket', refers to an automobile that is decrepit, rundown and often of minor quality (e.g. unreliable in its functioning).
} 
level of the system - inherent to the current system of automobility itself [e.g. for visions and projects on the European Union level, see 43, 44]. These challenges are: (1) compromised safety with thousands of deaths in many countries around the world; (2) consumption and pollution through the transportation sector-which is to a large extent personally used automobiles - that is one of the primary consumers of petroleum based fuels and with that a large emitter of greenhouse gas emissions; and (3) inefficiency and congestion, in particular in the many metropolitan regions throughout the world. Fully automated driving is considered to address these challenges by (1) replacing what is related to as a 'safety risk' for car driving, namely the human that brings in elements like distraction, fatigue, risky behavior, etc. [45, 46], by (2) controlling vehicles to drive more smoothly and efficiently, thereby improving fuel economy [47], and by (3) eliminating human caused backups with the help of automatically controlled vehicles that can reduce time gaps between vehicles and increase overall traffic flows (especially when coordinated by a traffic management center or by utilizing vehicle-to-vehicle communication) [48]. Yet, several questions - e.g. concerning technical challenges, regulatory frames, economic benefits, user and societal acceptance, etc.- - remain unanswered and the above mentioned prospects, highly depending on these issues, currently portray visionary statements rather than empirically secured certainties. ${ }^{5}$ It is therefore not yet clear what precise consequences could come along by implementing self-driving technology into our transport system - in relation to travel behavior, land use, access to mobility, car related industries, insurance policies, etc. - and not much academic research has been devoted to these topics so far. ${ }^{6}$ There has been, however, due to the growing interest in the topic, an increasing number of studies and reports from consulting firms [e.g. 49-52] as well as from other institutions [e.g. 2, 53], mainly aiming at advising policy makers and industry [cf. 52]. Taken together, current research on automated driving often tends to focus on the technical parts of the technology emerging and mostly originates from technical perspectives/ disciplines. We will in the following emphasize the context of the system where the technology is likely to be embedded in and focus on current trends, developments and actors that tend to play a role in the genesis of fully automated driving (see

\footnotetext{
$\overline{{ }^{5} \text { For example, }}$ projections for the safety potentials of fully automated vehicles are subject to various assumptions about variables that are currently unknown and therefore need to be validated and refined carefully [46]. Also, the varying vocabulary used ("driverless", "self-driving", "autonomous", "automated", "intelligent", etc.) could be misleading and distracting to assess benefits and consequences of autonomous driving technology in general.

${ }^{6}$ An exception presents the research project "Autonomes FahrenFörderprojekt Villa Ladenburg”, funded by the Daimler and Benz foundation (for more information, see in the text) - worldwide probably the most comprehensive project in academia so far, with a broad scope on fully automated driving.
}

Fig. 2 for a graphic overview of the scenarios with regard to their actual players and their assumed ambitions). We will discuss three different deployment scenarios of fully automated driving — namely 'evolution', 'revolution' and 'transformation'-based on what is currently known. Essentially, the study used an explorative approach: between October 2012 and September 2014, expert views and studies from industry and academia were discussed in six expert workshops and through the adaption of work packages by various experts from different disciplines. The overall aim of the project, funded by the Daimler and Benz foundation, was to anticipate and motivate a broader debate on automated driving from interdisciplinary viewpoints [54]. The discussions and topics were organized in matrixes and then compiled in specific use cases of fully automated driving [55] as well as different deployment scenarios [56]. Out of this, classifications of automated driving could be conducted, based on levels of automation ('partly automated' to 'fully automated'), application fields ('restricted' to 'not restricted'), actors involved and mobility concepts. By introducing the three scenarios, their possible requirements and consequences, we want to bring attention to a rapidly changing technological landscape and add to the discussion on possible shifts and ruptures in the system of automobility (see above). However, as we will show in the following section, several elements as well as their dynamics in the technological field currently remain nebulous, thereby making it difficult to assess or even forecast transition processes. What we will provide, though, is a first overview on prevailing developments that can initiate a broader scientific debate on fully automated driving for the future.

\section{Evolution of the personal automobile}

One scenario towards fully automated driving, and potentially the most obvious one, is the evolution of the personal automobile, which implies that the vehicle will be complemented with technology assisting and eventually replacing the driver [cf. 57, 58]. This scenario has its technological roots in what is called 'Driver Assistance Systems', e.g. anti-lock braking, stability control, adaptive cruise control, lane keeping assist, emergency braking assist, parking assist, and now currently the deployment of traffic jam assist [cf. 59, 60]. As these terms suggest, the respective systems for now assist the driver (and do not perform independently) in specific situations, which can be categorized as too unfamiliar, too demanding or too tedious to be performed by a human - whereas the tentative end of this pathway is a passenger vehicle on the highway that drives itself or maneuvers into a parking spot with no human interaction necessary $[61,59]$. Primary players in this field are established vehicle manufacturers and component suppliers, both often in collaboration with additional players in industry and academia, aiming to continuously improve safety and convenience of their products, i.e. personally used 
Fig. 2 Overview of three primary deployment scenarios for fully automated driving

\section{EVOLUTION}

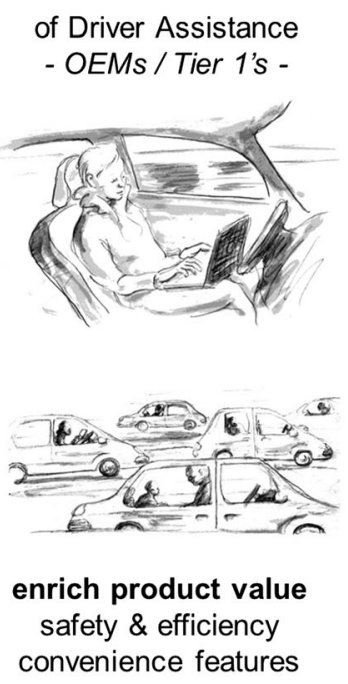

REVOLUTION

of Automobile Usage - IT Companies -
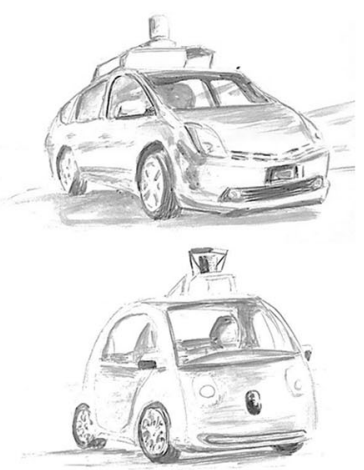

more market share mobility data \& service internet while driving
TRANSFORMATION

of Personal Mobility - Startups, Services -
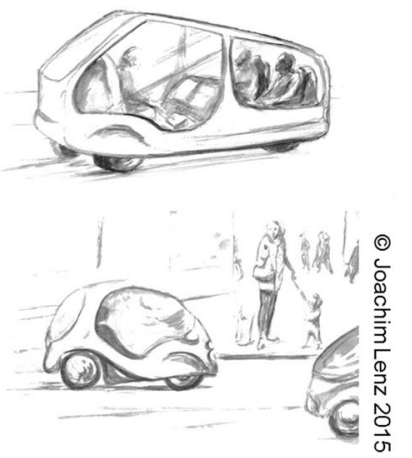

create new business mobility on-demand last/first mile solution automobiles. This scenario follows the approach how the automotive industry typically introduces innovation, which is in a stepwise manner in the pursuit of keeping a competitive advantage in the market [cf. 57, 62, 63]. However, it is considered demanding, that the introduction of automated driving technology will require a shift in how humans interact with vehicles and what infrastructure as well as regulatory measures might be necessary $[1,2]$.

One of the key elements, and challenge simultaneously, therefore seems to be the human-machine interface: the evolutionary steps from a scenario where the driver constantly monitors the vehicle to a scenario where she/he only needs to be present in case of an unforeseen situation to the fully automated scenario where no monitoring and no intervention are necessary any more, pose difficulties to interface developers as well as to engineers and human-machine psychologists $[64,65]$. Simultaneously, drivers' trust in a machine seems to depend largely on the machine's ability to mimic humanity - e.g. having names, a gender, a voice — known under the concept of 'anthropomorphism' [cf. 66]. Thus, the vivification of machines could increase with the advent of the fully automated vehicle as lines between the human and the nonhuman become more and more blurry.

Another complicacy poses mixed traffic to this scenario: While only few new vehicles would be 'quasi self-driving', many existing vehicles would still be entirely human controlled. How to implement safeguards in vehicle and roadway systems to cope with mixed traffic will be a technical, regulatory and infrastructural challenge for the evolutionary scenario towards automated driving.

With regard to the multi-level perspective (MLP), the pathways to this scenario could be described as either transforming or reconfiguring the existing regime, more from within the regime itself than from landscape, niche or outside forces [23].
On the landscape level, moderate pressure can be stated-e.g. climate change and urbanization processes, i.e. rising congestion problems as a result of spatial agglomeration. On the regime level, this already lead to increased initiatives towards greener, less congested cities [e.g. 67], thereby also exerting pressure on regime actors like vehicle manufacturers to adjust their products (i.e. technologies related to road vehicles) to the stated challenges [47]. An evolution of automobiles that become less and less human-operated will eventually modify practices of using the car, being in the car, perceiving travel time, etc. A gradual adaptation on the regime level is therefore conceivable for the evolutionary scenario, though a fundamental change of the system cannot be anticipated at the moment.

This adds to the discourse of the car as the predominant means of transportation, embedded in what is conceptualized by Urry "as a self-organizing autopoietic, non-linear system" $[11$, p. 27]. As such, this system has been able to adapt to changing environments (e.g. technological, political, infrastructural, social) and reproduce its predominance continuously. When a CEO of a large vehicle manufacturer introduced a concept car at the Consumer Electronics Show in Las Vegas in January 2015, that showed their vision about the future fully automated car, he supported his keynote speech by key phrases like "private space and quality time", "luxury", "exclusive cocoons on wheels", "space, time and privacy", "third place [...] in addition to home and office" [68]—weaving it in with what seems to be a logical evolution of the automobile. Showcase phrases like these therefore represent leading paradigms for the evolutionary scenario and can be read as interesting hints that the era of the car might not be over yet. Even the opposite could hold true: an automated driving cocoon can be read as a metaphor for a private resort that enables escaping from modern life, often sensed as stressful, noisy, speedy and crowded. In this context, driving in a car 
could unfold further significance in relation to social interaction within the inside space of the vehicle [cf. 69 ${ }^{7}$ - simultaneously, the (formerly self-driving) individual will be teared from other social interactions on the outside even further, e.g. the street life, traffic, environment, etc.

\section{Revolution of personal mobility}

While the evolutionary scenario seems to be relatively obvious as a pathway toward fully automated driving, there is another much discussed trend that can be described as 'nonautomotive technology companies entering the field': Players with a background in the internet search and online services business now aim to apply their expertise in data systems, mapping technology, and artificial intelligence to the mobility field. The goal seems to induce a fundamental change in how individuals use personal mobility - a revolution. In contrast to the evolutionary scenario, no steps between current driving modes and fully automated driving are intended, and a completely different traffic pattern is envisioned altogether [cf. 70, 71]. Although, it is not yet clear if-similar to the evolutionary scenario - a broad coverage of highways should be expected for this scenario or rather a limited deployment, for instance only on reserved highway lanes or in specific downtown areas; the latter might be more likely, considering some of the companies' research activities [72, 73].

Besides implementing their technology solutions in other fields, a key motivation for the non-automotive technology companies seems to be the extension of respective core products, i.e. internet services and online businesses, to what could arguably be called the final frontier of the digital lifestyle, i.e. the time and place when consumers drive an automobile. In this sense, a fully automated vehicle is a means of movement that not only blurs the lines between human and machine, but one that blurs the lines between human, machine and computer/information systems.

While the challenges regarding the evolutionary scenario are somewhat scenario inherent, i.e. the mixed traffic situation during the transition toward fully automated driving, this seems to be different with the revolutionary scenario. Assuming that a limited deployment of fully automated vehicles in dedicated areas - e.g. on a few city blocks or on a few highways - is at least a likely pathway towards this scenario, a necessary infrastructure can be deployed more easily for this limited scope than it would be the case for a large network of city streets and highways, meaning that the revolutionary scenario might earlier come to fruition than the evolutionary one.

\footnotetext{
${ }^{7}$ A liberation from the driving task fits in with cars' evolutionary development over recent decades where a trend could be observed that driving is far less a matter of expressing identity (as also manifested in sports cars' loss of significance and the increase in closed vehicles with large interiors) than one of temporarily 'inhabiting' a space that also enables social interaction [69].
}

Although this scenario could be regarded as coming from the niche level within the system of automobility (e.g. considering the research activities and the test beds [73]), the key players could rather be seen as established within the regime of another system, namely the 'system of information and communication' [31]. However, the business models that these players pursue currently remain rather nebulous: it is highly uncertain if companies from the information technology sector could (or even plan to) eventually replace the established OEM and take over the car manufacturing field. In fact, companies like Google currently seem to be the only ones officially promoting a fully automated vehicle that does not have pedals and a steering wheel anymore [74], while OEM focus more on automated assisting features that eventually, but only in the long-term lead to fully automated vehicles [56]. This tentativeness currently leaves room for a lot of speculation not only on the possible scenarios but also on the potential consequences [56]. Changes on the regime level of the system of automobility are therefore conceivable for many of the regime's (material or immaterial) elements: company takeovers or cooperation could alter the landscape of actors in the system, influencing technical products and (mobility) services, thereby influencing the meaning and ascription of automobiles [75]; automobile user practices could adjust, and "how the car is inhabited can be transformed" [69, p. 237], etc. One thing seems to be certain, though: the digitalization of many parts of our societies does (or probably will) not spare the mobility sector in general [75].

\section{Transformation of personal mobility}

Finally, a third scenario towards fully automated driving aims at reinventing personal mobility by combining the advantages of the personally used automobile and public transportation, addressing the 'last mile' problem, and further enhanced by advanced technology. The key players in this field are startup and service companies that pursue new business opportunities. The goal is to automate taxi and ride-sharing services, i.e. to offer so-called 'automated mobility on-demand' (AMOD) services, which consist of a fleet of self-driving vehicles that can be ordered to the user's location to be then transferred to a desired destination, all within a pre-defined operating area. Currently there are several pilot deployments of AMOD systems in Switzerland, Singapore, or England [e.g. 76, 78].

On the one hand, this scenario is similar to the revolutionary scenario as it aims at changing mobility patterns in a limited deployment area (such as a specific downtown district). On the other hand, however, the primary focus here is to establish a completely new way of personal mobility - closely interrelated to the use of information and communication technologies (e.g. that enables fast access to vehicles or mobility services). It does not just aim to revolutionize the way that people use the automobile as we know it, but rather integrate 
personal mobility with public transportation to address safety, pollution, and congestion problems. The respective startup or service companies are driven by the idea that the personally owned and operated automobile is more and more impractical if not completely unsustainable in cities, but at the same time the public transportation network of trains and buses is not seamless enough so that a convenient door-to-door coverage can be offered. Therefore, the transformative scenario could be regarded as on the edge of technological and social innovation to address problems that individual motorized traffic brought to the fore, advanced by a very active startupcommunity around (shared) mobility options that constantly develops digital applications for connected and intermodal transportation options [cf. 79].

AMOD systems might in some cases just cover the first/last mile segment of an inner-city trip (i.e. to/from the subway station) and in other cases enable a practical way to implement a convenient public transportation system in the first place. It could also serve as an expansion and differentiation of today's car sharing concepts where one of the main hurdles remain in that the user has to catch the vehicle - with fully automated vehicles it could be the other way round: the vehicle catches the user [80, p. 177]. This, at first glance, could indeed offer new potentials to change current automobile practices (as well as the meanings that are currently ascribed to an automobile) on the regime level: instead of using and owning an automobile, users of fully automated vehicles could order a car whenever they need it, or access other means of transport if these seem to suit their mobility needs in a better way.

Alongside the above-mentioned changes on the regime level from the other scenarios that might as well play out for the transformative scenario, also come changes that arise from the hybridization of individual and public transport. The likelihood of local transport authorities engaging more in cooperation with private mobility providers might lead to renegotiating rules, regulations and access in the public transport arena, thus retroacting on "knowledge and discourses, their sedimentation in material landscapes, institutions and laws to governmentalities, subject formations and empirical practices" [18, p. 619].

One challenge concerning the transformative scenario actually seems to lie in establishing initial deployments of AMOD systems, coming from a niche, in public, so that the benefits and practicality of this approach can be demonstrated. The key players behind this scenario hope to generate demand for respective solutions so that significant R\&D efforts can be spread over multiple deployments and can be recovered altogether. This presents a typical startup problem, which is that innovative companies pursue a novel business idea, often involving novel technology and aiming to transform the existing, but don't have too much leverage on the market. In addition, similar to the other two before mentioned scenarios, infrastructure measures in terms of regulation, communication, and roadways might be necessary, which need to be established first, even if only on a very local level. Overall, this scenario might come to fruition in a similar time horizon as the revolutionary scenario, which is well before the evolutionary example because only limited deployment areas are targeted.

\section{Conclusion}

Obviously, the three scenarios to fully automated driving are rather complementary than competitive, they could therefore as well evolve parallel to each other. However, their implications for the system of automobility could be quite different. While the evolutionary scenario seems to lead to a slow transformation or reconfiguration of the system on the regime level without changing current mobility patterns [cf. 31, pp. 335], and the transformative scenario might imply a different regime where multimodal practices replace the predominance of the privately owned car (ibid.), the direction of the revolutionary scenario remains rather nebulous - in part, because it is not clear yet what the objectives and the scope of the dominant players are. It is therefore challenging and due to further research to evaluate the consequences that an amalgamation of two systems, i.e. the system of automobility and the system of information and communication technologies could implicate in the mid and long term.

For reasons of the scale of (first) implementation, it can be expected that the easiest (i.e. the transformative scenario) might yield pilot deployments of fully automated urban mobility services in form of AMOD in the very near term (within a few years), the revolutionary scenario can be expected in the midterm (by the end of this decade), and the evolutionary scenario might only get to a level meeting the fully automated driving definition in the very long term (it does not seem realistic at this point to make projections that far into the future, therefore a concrete date should not be stated).

Challenges that the different scenarios face are somewhat similar, as infrastructure measures are needed to establish respective legal, communication, and roadway systems recognizing the special needs of fully automated vehicles. While regulators have to learn how to regulate a new traffic pattern with fully automated vehicles, the general public also needs to learn how to interact with such new concepts. Today's traffic has actually, with all its challenges, become something intuitive and natural. That means eye contact, courtesy, intuition, and common sense help humans to participate in traffic. And going forward, a new behavior needs to be established if more and more non-human behavior is added to the mix. Trust, ethics, and hierarchy might change as humans hand over more and more control to machines, which is something that can also be observed in other fields of robotics, such as the manufacturing realm. 


\section{Outlook}

The remarks on the three scenarios necessarily remain on a fragmentary base - be it technical, legal, infrastructural, behavioral or societal questions, challenges and measures, there certainly is more that could be discussed. Yet, the items mentioned above should have served to initiate a start on a more holistic debate on a future with fully automated vehicles and their implications in a larger context, i.e. in the system of automobility. So far, fully automated driving has been - besides from the technological aspects - researched scarcely and the considerations on the three scenarios also originate from a technological perspective, respectively developments in the technological sectors. Yet, different scenarios - this is what we wanted to outline - could have different implications, not only in relation to the technical artefact (the automobile) and its future users but for the system of automobility as a whole. Such a systemic research approach thereby maneuvers on the interface of different scientific disciplines, or, to put it in other words: if fully automated driving is considered to play a significant role in future mobility possibilities, "it should not be restricted to an arena primarily concerned with technical and legal questions" [81, p. 170]. Technological developments blur lines between technology, society and nature, which is a reason why they are only to be solved by close interdisciplinary work.

In our study, the multi-level perspective (MLP) was used to identify and examine current developments in the field of automated driving. As stated in "New technologies in relation to sociotechnical transformation processes", the MLP can be characterized as an explanatory and analytical approach to investigate sociotechnical changes and to emphasize specific characteristics and dynamics on various levels (landscape, regime, niche) that lead to these changes $(20$, p. 38). However, the approach tends to unduly generalize the characteristics and dynamics into patterns, thereby suppressing "how technical systems are implicated in defining and reproducing daily life" (21, p. 471) whereas the examination of "heterogeneity, contingency, fluidity, emergence, unpredictability, and untidiness" (20, p. 38 ) as well as the formation/configuration of altered social practices and routines that enable technological change may be an inevitable amendment to get a more holistic picture.

Admittedly, working concepts, theoretical and methodical approaches that fit social sciences, engineering and the sciences likewise to gain this 'holistic picture' are hard to find. An example for such an approach would be the 'constellation analysis' as "an interdisciplinary Bridge-Concept" [cf. 82, p. 1] that tries to equally integrate bodies of knowledge, viewpoints and investigative horizons of different disciplines from a bottom-up perspective. Furthermore, and as recently stated by Schirrmeister [83], discourse-analytical approaches seem to be very well suited for research on future technologies: "Although the theoretical background and methodological approach may differ, [...] discourse analysis could be an appropriate method for investigating different subjects without being restricted to the perspective of a single scientific discipline alone" (ibid., p. 2). Certainly, focusing on the discursive formations as (re)productions of knowledge and their linguistic elements alone would encumber the view on what Foucault from a more holistic perspective described as 'dispositif': a net of material structures, discourses, practices and subjective positioning [84, p. 194]. In her recent work on possible changes within the system of automobility and the emergence of new mobility regimes, Manderscheid [18] picks up on Foucault's concept of the dispositif and provides interesting and integral insights that could as well be suitable when analyzing implications of fully automated driving in the future. Based on these assumptions one could state that " a broad societal learning process is needed, with a focus on the system as a whole: its spatial characteristics, the infrastructural and technologic options, individual needs for mobility and access, cultural norms and institutions, as well as their mutual interdependence" [85, p. 1113].

Acknowledgments We would like to thank the Daimler and Benz foundation for funding part of the study.

Open Access This article is distributed under the terms of the Creative Commons Attribution 4.0 International License (http:// creativecommons.org/licenses/by/4.0/), which permits unrestricted use, distribution, and reproduction in any medium, provided you give appropriate credit to the original author(s) and the source, provide a link to the Creative Commons license, and indicate if changes were made.

\section{References}

1. Fagnant D, Kockelman K (2013) Preparing a nation for autonomous vehicles: opportunities, barriers and policy recommendations for capitalizing on self-driven vehicles. William P. Eno Paper. http:// www.caee.utexas.edu/prof/kockelman/public_html/ENOReport BCAofAVs.pdf. Accessed 24 June 2015

2. Litman T (2015) Autonomous vehicle implementation predictions - implications for transport planning. Victoria Transport Policy Institute. http://www.vtpi.org/avip.pdf. Accessed 24 June 2015

3. Pyper J, ClimateWire (2014) Self-driving cars could cut greenhouse gas pollution. Scientific American. http://www.scientificamerican. com/article/self-driving-cars-could-cut-greenhouse-gas-pollution/ Bullis, K. (2011): How Vehicle Automation Will Cut Fuel Consumption. October 24, $2011 \mathrm{http}$ ://www.technologyreview. com/news/425850/how-vehicle-automation-will-cut-fuelconsumption/. Accessed 14 Mar 2015

4. Hucko M (2015) Verkehrsplanung: "Selbstfahrende Autos sind eine Chance für die Stadt". Spiegel Online. http://www.spiegel. de/auto/aktuell/autonomes-fahren-chance-fuer-die-stadt-a-997393. html. Accessed 14 Mar 2015

5. Fung B (2014) The future of Google's driverless car is old people. The Washington Post. http://www.washingtonpost.com/blogs/theswitch/wp/2014/05/28/the-future-of-googles-driverless-car-is-oldpeople/. Accessed 14 Mar 2015

6. Kruse P (2009) Ein Kultobjekt wird abgewrackt. GDI Impuls 1: 12-20. http://www.z-punkt.de/fileadmin/be_user/D_News/D_ 2009_02_Newsletter/GDI_Impuls_1_09.pdf. Accessed $2 \overline{4}$ June 2015 
7. Fox WM (1995) Sociotechnical system principles and guidelines: past and present. J Appl Behav Sci 31:91-105

8. Latour B (1996) Aramis, or the love of technology. Harvard University Press, Cambridge

9. Geels FW (2005) The dynamics of transitions in socio-technical systems: a multi-level analysis of the transition pathway from horse-drawn carriages to automobiles (1860-1930). Tech Anal Strat Manag 17:445-476

10. Lyons G (2012) Visions for the future and the need for a social science perspective in transport studies. In: Geels FW, Kemp R, Dudley G, Lyons G (eds) Automobility in transition?-a sociotechnical analysis of sustainable transport. Routledge, New York et al., pp 29-48

11. Urry J (2004) The 'system of automobility'. Theory Cult Soc 21:25-39

12. De Haan J, Rotmans J (2011) Patterns in transitions: understanding complex chains of change. Technol Forecast Social Chang 87:90-102

13. Morton C, Schuitema G, Anable J (2011) Electric vehicles: Will consumers get charged up? 43nd Annual UTSG Conference. http:// www.academia.edu/5439476/Electric_Vehicles_Will_consumers get charged up. Accessed 14 Mar 2015

14. Smith A, Voß JP, Grin J (2010) Innovation studies and sustainability transitions: the allure of the multi-level perspective and its challenges. Res Policy 39:435-448

15. Genus A, Coles AM (2008) Rethinking the multi-level perspective of technological transitions. Res Policy 37:1436-1445

16. Rotmans J, Kemp R, Asselt MV (2001) More evolution than revolution: transition management in public policy. Foresight 3:15-31

17. Joas H, Knöbl W (2004) Sozialtheorie: Zwanzig einführende Vorlesungen. Suhrkamp, Frankfurt am Main

18. Manderscheid K (2014) The movement problem, the car and future mobility regimes: automobility as dispositif and mode of regulation. Mobilities 9:604-626

19. Geels F (2010) Ontologies, socio-technical transitions (to sustainability), and the multi-level perspective. Res Policy 39(4):495-510

20. Verbong GP, Geels F (2010) Exploring sustainability transitions in the electricity sector with socio-technical pathways. Technol Forecast Soc Chang 77(8):1214-1221

21. Geels F (2011) The multi-level perspective on sustainability transitions: responses to seven criticisms. Environ Innov Societal Transit 1:24-40

22. Shove E, Walker G (2010) Governing transitions in the transitions in the sustainability of everyday life. Res Policy 39:471-476

23. Geels F, Schot J (2007) Typology of sociotechnical transition pathways. Res Policy 36(3):399-417

24. Berkhout F, Smith A, Stirling A (2003) Socio-technological regimes and transition contexts. SPRU Electron Working Paper Series 106:1-36

25. Latour B (2005) Reassembling the social: an introduction to actorNetwork-theory. Oxford University Press, Oxford

26. Thrift N (2004) Driving in the City. Theory Cult Soc 21:41-59

27. Bull M (2001) Soundscapes of the Car: A Critical Ethnography of Automobile Habitation. In: Miller D (ed) Car cultures. Berg Publishers, Oxford, pp 185-202

28. Gilroy P (2001) Driving While Black. In: Miller D (ed) Car cultures. Berg Publishers, Oxford, pp 81-104

29. Stotz G (2001) The Colonizing Vehicle. In: Miller D (ed) Car cultures. Berg Publishers, Oxford, pp 223-243

30. Böhm S, Jones C, Land C, Paterson M (2006) Introduction: impossibilities of automobility. Sociol Rev 54:1-16

31. Geels F, Kemp R, Dudley G, Lyons G (2012) Automobility in transition? - a socio-technical analysis of sustainable transport. Routledge, New York

32. Goodwin KJ (2010) Reconstructing automobility: the making and the breaking of modern transportation. Glob Environ Polit 10:60-78
33. OECD, International Transport Forum (2013) Long-run trends in car use. ITF Round Tables No. 152, OECD Publishing/ITF. doi:10. 1787/9789282105931-en. Accessed 14 March 2015

34. Chen Q, Le Vine S, Polak J (2014) Generation Next. The changing travel habits of pre-driving age young people in Britain. The Royal Automobile Club Foundation (RAC), London

35. Feige I, Kuhnimhof T (2013) 'Mobility $\mathrm{Y}$ ' - the emerging travel patterns of generation Y. Institute for Mobility Research (ifmo), München

36. Kent J (2014) Driving to save time or saving time to drive? The enduring appeal of the private car. Transp Res A 65:103-115

37. Sheller M (2004) Automotive emotions feeling the car. Theory Cult Soc 21:221-242

38. Kubitzki J (2014) Jung und urban. Sicherheit und Mobilität 18-24Jähriger im motorisierten Straßenverkehr. Allianz Deutschland AG, München

39. Becker J (2015) So schnell rostet Autoliebe nicht. Süddeutsche.de. http://www.sueddeutsche.de/auto/zukunft-des-fahrens-so-schnellrostet-autoliebe-nicht-1.2285713. Accessed 14 March 2015

40. Kröger F (2015) Das automatisierte Fahren im gesellschaftsgeschichtlichen und kulturwissenschaftlichen Kontext. In: Maurer M, Gerdes JC, Lenz B, Winner H (eds) Autonomes Fahren. Technische, rechtliche und gesellschaftliche Aspekte. Springer Vieweg, Wiesbaden, pp 41-68

41. Minx E, Dietrich R (2015) Geleitwort. In: Maurer M, Gerdes JC, Lenz B, Winner H (eds) Autonomes Fahren. Technische, rechtliche und gesellschaftliche Aspekte. Springer Vieweg, Wiesbaden, pp V-VII

42. SAE International (2014) Automated driving levels of driving automation are defined in New SAE International Standard J3016. SAE International. http://templatelab.com/automated-driving/. Accessed 14 March 2015

43. Highly Automated Vehicles of Intelligent Transport (HAVEit): Project, part of the 7th RTD Framework Programme of the European Union (FP7-ICT - Information and Communication Technologies. http://www.haveit-eu.org Accessed 24 June 2015

44. European Road Transport Research Advisory Council (ERTRAC) (2013) Multi-annual implementation plan for horizon 2020. http:// w w w. e r t r a c. org/i n d ex. p h p ? m a c t $=$ DocumentSearch,cntnt01,default, $1 \&$ cntnt01documentsearch id= $20 \&$ cntnt01 returnid $=88 \&$ page $=88$. Accessed 24 June 2015

45. Burns L (2013) Sustainable mobility: A vision of our transport future. Nature 497: 181-182. http://www.nature.com/nature/ journal/v497/n7448/full/497181a.html. Accessed 24 June 2015

46. Winkle T (2015) Sicherheitspotenzial automatisierter Fahrzeuge: Erkenntnisse aus der Unfallforschung. In: Maurer M, Gerdes JC, Lenz B, Winner H (eds) Autonomes Fahren. Technische, rechtliche und gesellschaftliche Aspekte. Springer Vieweg, Wiesbaden, pp $351-376$

47. Hönle S (2015) Connected \& Automated Driving. ERTRAC 2015 Annual Conference. http://www.ertrac.org/uploads/documents publications/2015\%20Conference\%20presentations/Bosch.pdf. Accessed 24 June 2015

48. Friedrich B (2015) Verkehrliche Wirkung autonomer Fahrzeuge. In: Maurer M, Gerdes JC, Lenz B, Winner H (eds) Autonomes Fahren. Technische, rechtliche und gesellschaftliche Aspekte. Springer Vieweg, Wiesbaden, pp 331-350

49. Silberg G, Wallace R, Matuszak G (2012) Self-driving cars: The next revolution. KPMG. https://www.kpmg.com/US/en/ IssuesAndInsights/ArticlesPublications/Documents/self-drivingcars-next-revolution.pdf. Accessed 42 June 2015

50. Leech J, Whelan G, Bhaiji M (2015) Connected and autonomous vehicles - The UK Economic Opportunity. KPMG. http://www. smmt.co.uk/wp-content/uploads/sites/2/CRT036586F-Connectedand-Autonomous-Vehicles- $\%$ E2\%80\%93-The-UK-EconomicOpportu...1.pdf. Accessed 24 June 2015

51. Diem W (2013) Driver assistance to driverless cars: technologies, challenges and outlook. Autelligence limited 
52. Anderson J, Kalra N, Stanley K, Sorenson P, Samaras C, Oluwatola O (2014) Autonomous Vehicle Technology. A Guide for Policymakers. RAND Corporation, http://www.rand.org/content/ dam/rand/pubs/research_reports/RR400/RR443-1/RAND_RR4431.pdf. Accessed 24 June 2015

53. Le Vine S, Polak J (2014) Automated cars: a smooth ride ahead? ITC Occasional Paper. Number Five. Independent Transport Commission (ITC). http://www.theitc.org.uk/docs/114.pdf. Accessed 24 June 2015

54. Maurer M, Gerdes JC, Lenz B, Winner H (2015): Autonomes Fahren. Technische, rechtliche und gesellschaftliche Aspekte, Springer Vieweg, Wiesbaden http://link.springer.com/book/10. 1007\%2F978-3-662-45854-9. Accessed 24 June 2015.

55. Wachenfeld W, Winner H, Gerdes JC, Lenz B, Maurer M, Beiker S, Fraedrich E, Winkle T (2015) Use-cases des autonomen Fahrens. In: Maurer M, Gerdes JC, Lenz B, Winner H (eds) Autonomes Fahren. Technische, rechtliche und gesellschaftliche Aspekte. Springer Vieweg, Wiesbaden, pp 9-37

56. Beiker $\mathrm{S}$ (2015) Einführungsszenarien für höhergradig automatisierte Straßenfahrzeuge. In: Maurer M, Gerdes JC, Lenz B, Winner H (eds) Autonomes Fahren. Technische, rechtliche und gesellschaftliche Aspekte. Springer Vieweg, Wiesbaden, pp 197-217

57. Becker J, Aranda Colas M-B, Nordbruch S, Fausten M (2014) Bosch's Vision and Roadmap Toward Fully Autonomous Driving. In: Meyer G, Beiker S (eds) Road vehicle automation. Springer International Publishing, Wiesbaden, pp 49-59

58. Continental (2012) Continental strategy focuses on automated driving. Press release. https://www.conti-online.com/www/pressportal com_en/themes/press_releases/1_topics/automated_driving_en/pr $2012^{-} 1218$ automated driving en.html. Accesses 24 June 2015

59. Daimler: Mercedes-Benz Intelligent Drive - On the road to autonomous driving. avoiding danger, providing timely warning and assisting. http://www.daimler.com/dccom/0-5-1210218-11462148-1-0-0-1210228-0-0-0-0-0-0-0-0-0-0-0.html. Accessed 24 June 2015

60. BMW: Traffic jam assistant. http://www.bmw.com/com/en/ newvehicles/x/x5/2013/showroom/driver_assistance/traffic_jam assistant.html\#t=1. Accessed 24 June 2015

61. Nissan (2013) Nissan Announces Unprecedented Autonomous Drive Benchmarks. Press Release. http://nissannews.com/en-US/ nissan/usa/releases/nissan-announces-unprecedented-autonomousdrive-benchmarks. Accessed 24 June 2015

62. ESC Installation Rates Worldwide by New Car Registration", Bosch Unternehmenswebseite, http://www.bosch.co.jp/en/press/ pdf/rbjp-1009-02-01.pdf

63. McBride, B., "Vehicle Sales: Fleet Turnover Ratio", Calculated Risk, http://www.calculatedrisk-blog.com/2014/09/vehicle-salesfleet-turnover-ratio.html. Accessed 24 June 2015

64. Wolf I (2015) Wechselwirkung Mensch und autonomer Agent. In: Maurer M, Gerdes JC, Lenz B, Winner H (eds) Autonomes Fahren. Technische, rechtliche und gesellschaftliche Aspekte. Springer Vieweg, Wiesbaden, pp 103-126

65. Färber B (2015) Kommunikationsprobleme zwischen autonomen Fahrzeugen und menschlichen Fahrern. In: Maurer M, Gerdes JC, Lenz B, Winner H (eds) Autonomes Fahren. Technische, rechtliche und gesellschaftliche Aspekte. Springer Vieweg, Wiesbaden, pp $127-146$

66. Waytz A, Heafner J, Epley N (2014) The mind in the machine: anthropomorphism increases trust in an autonomous vehicle. $\mathrm{J}$ Exp Soc Psychol 52:113-117

67. Siemens AG (2012) The Green City Index. A summary of the Green City Index research series. http://www.siemens.com/entry/ cc/de/greencityindex.htm Accessed 24 June 2015
68. Zetsche D (2015) Dr. Dieter Zetsche - Mercedes-Benz KEYNOTE 2015. International CES 5.01.2015. https://www. youtube.com/watch?v=cMmYFxe6O-I. Accessed 14 March 2015

69. Laurier E, Dant T (2012) What We Do Whilst Driving: Towards the Driverless Car. In: Grieco M, Urry J (eds) Mobilities: new perspectives on transport and society. Ashgate, Hampshire, pp 223-244

70. Thrun S (2010) What we're driving at, Official Google Blog, http:// googleblog.blogspot.de/2010/10/what-were-driving-at.html Accessed 24 June 2015

71. Ingram A (2014) Nokia Joins Autonomous Car Development With \$100M Fund“, Motorauthority, http://www.motorauthority.com/ news/1091948_nokia-joins-autonomous-car-development-with100m-fund. Accessed 24 June 2015

72. Ramsey M (2015) Carnegie mellon reels after uber lures away researchers. The Wall Street Journal. http://www.wsj.com/articles/ is-uber-a-friend-or-foe-of-carnegie-mellon-in-robotics1433084582. Accessed 24 June 2015

73. Fehrenbacher K (2013) Zappos CEO rethinks urban transportation in Vegas with 100 Tesla Model S cars, Gigaom. https://gigaom. com/2013/04/03/zappos-ceo-rethinks-urban-transportation-invegas-with-100-tesla-model-s-cars/

74. Google Self-Driving Car Project. Official Website. http://www. google.com/selfdrivingcar/. Accessed 26 June 2015

75. Rammler S (2015) Doppelter Fahrerwechsel in der Autobranche. In: Zeit Online. http://www.zeit.de/mobilitaet/2015-02/applegoogle-auto-digitalisierung. Accessed 24 June 2015

76. Caula R (2014) AKKA link\&go 2.0 electric self-driving concept designed for future cities, http://www.designboom.com/ technology/akka-linkgo-2-0-electric-driverless-concept-car-forthe-city-of-the-future-03-12-2014/ Accessed 24 June 2015

77. CityMobil2 (2012) CityMobil2 http://www.citymobil2.eu/en/. Accessed 14 March 2015

78. Milton Keynes (2014) Driverless Pods: first three to arrive in Milton Keynes in March - and fleet of 40 will follow soon after. MK News. http://www.mkweb.co.uk/DRIVERLESS-PODSarrive-Milton-Keynes-March/story-25155183-detail/story.html. Accessed 14 March 2015

79. Silicon Valley Autonomous Vehicle Enthusiasts: Official Website. http://www.meetup.com/de/Silicon-Valley-Autonomous-VehicleEnthusiasts/. Accessed 24 June 2015

80. Lenz B, Fraedrich E (2015) Neue Mobilitätskonzepte und autonomes Fahren: Potenziale der Veränderung. In: Maurer M, Gerdes JC, Lenz B, Winner H (eds) Autonomes Fahren. Technische, rechtliche und gesellschaftliche Aspekte. Springer Vieweg, Wiesbaden, pp 175-196

81. Schreurs M, Steuwer S (2014) Autonomous Driving - Political, Legal, Social, and Sustainability Dimensions. In: Maurer M, Gerdes JC, Lenz B, Winner H (ed) Autonomes Fahren. Technische, rechtliche und gesellschaftliche Aspekte. Springer Vieweg, Wiesbaden, pp 151-174

82. Schön S, Nölting B, Meister M (2004) Konstellationsanalyse. Ein interdisziplinäres Brückenkonzept für die Technik-, Nachhaltigkeits- und Innovationsforschung. Discussion Paper 12. Zentrum für Technik und Gesellschaft, Berlin

83. Schirrmeister M (2014) Controversial futures - discourse analysis on utilizing the "fracking" technology in Germany. Eur J Futur Res 2(38):1-9

84. Foucault M (1980) Power/Knowledge. Selected Interviews and Other Writings 1972-1977. Pantheon Books, New York City

85. Vergragt PJ, Szejnwald Brown H (2007) Sustainable mobility: from technological innovation to societal learning. J Clean Prod 15: 1104-1115 